\title{
ESTABLISHING A NICHE IN RESEARCH: RHETORICAL STRATEGIES IN UNDERGRADUATE AND POSTGRADUATE WRITINGS IN THE DEPARTMENT OF ENGLISH, UNIVERSITY OF CAPE COAST
}

Christopher Ankomah, Joseph B. A. Afful

\author{
Department of English, Faculty of Arts, University of Cape Coast, Cape Coast, Ghana \\ E-Mail: krisanko31@gmail.com
}

\begin{abstract}
One key means of negotiating entry into a particular discourse in a research community is via the problem statement section in both research articles and dissertations/theses. Students are mostly confronted with the challenge of establishing a research space. This paper investigates the rhetorical strategies employed by Language students in the Department of English, University of Cape Coast, to establish a niche in their introduction sections. A total of fifty-two introductions were collected from both undergraduate dissertations and postgraduate theses. The data was subjected to a qualitative content analysis. The results of the analysis indicated that both undergraduate (UG) and postgraduate $(P G)$ students employed Indicating a Gap as their best choice to establish a niche, with the PGs using it more than the UGs. Both groups of students used Establishing Problem and Need as their next preferred option to create a research space. However, it was only the PGs who used Counter-claiming as the third strategy. These findings of this study have implications for the scholarship on students' academic writing and pedagogy.
\end{abstract}

Key words: Dissertation/thesis, introduction, niche, rhetorical strategies

\section{INTRODUCTION}

Research in any discourse community is crucial for its development and progress. Swales and Feak (2012: 284) claim that research papers (RP) "typically operate in a highly competitive environment" with other RPs for acceptance and high readership. Consequently, authors need to address interesting problems and questions (Ahltrom, 2017). It means that authors must demonstrate their familiarity with the literature so that what they intend answering does not become mere repetition of already existing knowledge (Neuman, 2007; Swales \& Feak, 2012). Researchers are expected to explicitly articulate the problem upon which their argumentation takes a firm stance. Zainudden and Shaari (2017) postulate that the most important element in the introduction of a research work is establishing the niche. For one to compose a well-written and successful research, the researcher needs to establish a formidable problem statement in the introduction. It is upon the construction of the problem that a study makes a considerable sense in a given field. It is based on a well-structured problem statement that almost all rhetorical sections of a research make sense. All parts of a research article (RA) are

Submitted July $17^{\text {th }}, 2019$, accepted for publication September $26^{\text {th }}, 2019$ 
mostly controlled from the problem that a study investigates. This means that it shapes rhetorical sections of a RA such as the title of a study, the aims, the research questions/hypotheses, the literature review, analysis and discussion, and conclusion.

Typically, it is the overall rhetorical shape of the problem statement that must sound persuasive to readers. For studies to be cited, the introduction plays a significant role by arousing the interest of the readers (Suryani et al., 2015). Swales and Feak (2012) indicate that studies that address new and relevant problems are cited more because of their potential contribution to scholarship. Editors and reviewers may find reasons to reject a RA if the introduction does not specifically indicate the purpose and the contribution it will make to the area of a field (Ahlstrom, 2017). Consequently, novice writers require the knowledge of best practices in problematising their problem in a RA, because the introduction section of research work poses serious challenges to writers (Afful, 2008; Bhatia, 1993; Suryani et al., 2015; Swales, 1990). Studies on the introduction section of RAs have focused mainly on its generic structure (e.g., Coker \& Coker, 2012; Davies, 2014; Farnia \& Barati, 2017; Jalilifar et al., 2011; Nimehchisalem et al., 2016; Parsa \& Tahririan, 2017; Shirani \& Chalak, 2016; Suryani et al., 2018), with few concentrating on Move 2, establishing a niche (e.g., Adika, 2014; Zainudden \& Shaari, 2017). Move 2 is crucial in constructing the introduction section and it indicates the main purpose of conducting a study (Adika, 2014; Farnia \& Barati, 2017). Besides, during such important speech events as proposal defence and thesis defence in the Department of English of UCC, students have to contend with the constant formidable question, "What is the problem statement of your study?".

Consequently, this study explores how undergraduate and postgraduate language students in the Department of English, UCC, Ghana, construct the problem statement of their research. This study, therefore, seeks to answer the following research questions.

1. What rhetorical strategies are used in establishing the niche of the introductions of undergraduate language dissertations and postgraduate theses in the Department of English?

2. What differences exist between the two groups of students in their use of rhetorical strategies in establishing a niche in research?

\section{LITERATURE REVIEW}

In this section, we review literature related to the current study. Specifically, the Create a Research Space (CARS) model which emanated from the genre theory is reviewed along with linguistic expressions and empirical studies surrounding the discourse of research problem statement.

\subsection{The CARS Model}

Create a research space (CARS) model was proposed by Swales (1990) on how researchers construct the introduction section of their RAs This model was created within the jurisdiction of genre theory, which relies on the communicative functions of texts. To fulfil the communicative purpose of the introduction section of RAs, the CARS model identified three main moves with steps under them: establishing a territory (Move 1/M1), establishing a niche (Move 2/M2) and occupying a niche (Move 3/M3). The first move 
creates the background to a topic being studied, by relying on the research area supported with reviewing previous research. The second move attempts to provide readers with information about the main motivation or issues, leading to the development of a new research. It indicates the need for undertaking a new research, regardless of previous studies in order to deal with unresolved issues. The third move announces the present study, suggesting what the present study focuses on. Figure 1 presents Swales CARS model.

\author{
Move 1: Establishing a territory \\ Step 1 Claiming centrality and or \\ Step 2 Making topic generalisation and or \\ Step 3 Reviewing items of previous research \\ Move 2: Establishing a niche \\ Step 1A Counter-claiming or \\ Step 1B Indicating a gap or \\ Step 1C Question-raising or \\ Step 1D Continuing a tradition \\ Move 3: Occupying the niche \\ Step 1A Outlining purpose or \\ Step 1B Announcing present research \\ Step 2 Announcing principal findings \\ Step 3 Indicating RA structure
}

Fig. 1 Creating a research space (CARS) model (Swales, 1990: 141)

Almost all studies that have investigated the introduction section of RAs (e.g., Adika, 2014; Coker \& Coker, 2012; Davies, 2014; Farnia \& Barati, 2017; Zainudden \& Shaari, 2017) employed the CARS model, either in its original state or modified form. The model has been found to be a viable tool for investigating rhetorical structures of academic writings. Therefore, this study employs the CARS model, especially M2 (Establishing a niche), in identifying the rhetorical choices in the data being studied. This is due to the fact that M2 speaks specifically to the rhetorical strategies used in problematising the problem of research works, the focus of the present study.

\title{
2.1.1. Lexico-Grammatical Choices
}

In constructing M2 (establishing a niche) in the problem statement section of a RP, different linguistic devices are employed to signal the need for a new study. The linguistic expressions show the uniqueness of how writers present M2 of their research works, and ways of persuading readers to accept the motivation of their studies. For instance, Swales and Feak (2012) provide different linguistic choices that appear prevalent in identifying M2, and useful guidance in constructing it. Although some of these expressions range from a quasi-negative (e.g., little, few) to full-negatives (e.g., no/none of), they are employed to signal a research space. Based on Swales and Feak (2012), we have organised some of these expressions into Figure 2. 


\begin{tabular}{|c|c|c|}
\hline Non-count & Count & Most Suitable Alternative \\
\hline Little attention . & Few studies & To the best of our knowledge ... \\
\hline Little work ........ & Few investigations ... & Research has tended to focus on ... \\
\hline Little data & Few researchers ...... & rather than on .... \\
\hline Little research ... & Few attempts ........ & $\begin{array}{l}\text { These studies have emphasised ... as } \\
\text { opposed to .... }\end{array}$ \\
\hline
\end{tabular}

Fig. 2 Some expressions used in establishing a niche (Source: Swales \& Feak, 2012)

Swales and Feak claim that the count and non-count expressions are quasi-negative but often used in establishing the niche of introductions. These authors suggest avoiding these negative expressions as much as possible in academic writing exercises. Besides, they contend that extremely negative expression like no studies must be avoided completely because some study might provide an exceptional case. They rather suggest that contrastive statements might be useful instead, as some can be found in the most suitable alternative column (Figure 2).

There are certain negative verbs and adjectives that are often used in establishing a gap in a study (Mahzari \& Maftoon, 2007; Swales \& Feak, 2012). Some of the verbs include: concentrated on, disregarded, ignored, misinterpreted, overlooked, neglected to consider, and others. Some of the adjectives comprise misguided, questionable, unconvincing, unsatisfactory or incomplete. These signalling expressions were useful in the current study, relative to the identification of the rhetorical strategies in the data.

\subsection{Related Studies on Establishing a Niche}

This section presents the review of empirical studies specific to establishing a niche in dissertations, thesis or RAs. The ideas are organised based on the rhetorical strategies used in establishing a niche. Generally, strategies that are found in Move 2/Establishing a niche of the CARS model include indicating a gap, counter-claiming, establishing need and problem, question raising, and continuing tradition (e.g., Lim, 2012; Suryani et al., 2018; Zainudden \& Shaari, 2017). Interestingly, Adika (2014) reports that $28.8 \%$ of Ghanaian writers did not indicate any explicit M2 in their RA introductions. Likewise, 'Establishing a Niche' did not appear as obligatory in all Spanish PhD theses studied (Salom et al., 2008; Soler-Monreal et al., 2011).

Varied reports are provided on the preference for 'Indicating a gap' strategy in establishing the niche of the introductions of RAs. For instance, Salom et al. (2008) report 'Indicating a gap' as the third highest strategy by Spanish PhD writers. However, different and inconsistent reports are provided in the context of Malaysia. All Ghanaian studies on 'Establishing a niche' show that Ghanaian writers prefer 'Indicating a gap' to other rhetorical strategies (Adika, 2014; Coker \& Coker, 2012; Davis, 2014). While 'Indicating a gap' strategy was found to be an obligatory and a first choice (Lim, 2012) and second frequently choice used by Malaysian PhD thesis writers (Zainudden \& Shaari, 2017), it was reported to be optional in RA introductions of Malaysian writers (Suryani, et al., 2018). In the context of Indonesia, writers preferred 'Indicating a gap' as their first choice, although not all that significantly different from 'Continuing tradition' strategy (Samad et al., 2017). Philippines research introductions also showed extremely first choice utilisation of 'Indicating a gap' strategy (Porras \& Ingilan, 2017). In another jurisdiction, whereas Parsa and Tahririan (2017) reported that native speakers of Persian 
prefer 'Indicating a gap' as their second-best choice in presenting the niche of their introductions, different studies found this same strategy as the writers' first choice (Farnia \& Barati, 2017; Mahzari \& Maftoon, 2007; Nimehchisalem et al., 2016). In Wuttisrisiriporn's (2017) comparative study of Thai and American MA theses, 'Indicating a gap' was the second-choice rhetorical strategy of the students. However, Mahzari and Maftoon (2007) showed that American RA introductions relied on 'indicating a gap' as their best option.

'Indicating problem and need' to establish a niche of research introductions has been reported to be a highly preferred choice. Just like Persian native speakers, as reported by Jalilifar et al. (2011) and Parsa and Tahririan (2017), Spanish writers make 'Indicating problem and need' their first choice in presenting their introductions of thesis (Salom et al., 2008). A similar finding was reported by Zainudden and Shaari (2017) that Malaysian writers indicated their first choice in establishing the niche of their introduction, using the strategy 'Indicating problem and need'. These findings establish that writers from different parts of the world, especially non-native speakers of English, prefer 'Indicating problem and need' in establishing a niche in situations where it is employed as part of rhetorical strategies. Wuttisrisiriporn's (2017) report demonstrates that not only do nonnative speakers of English like the Thai use 'Indicating problem and need' as their best choice, but also American MA students. It is more comfortable to use 'Establishing problem and need' to establish a niche (Wuttisrisiriporn, 2017), especially in the field of English teaching.

Generally, writers' use of 'Question-raising' appear infrequent as compared to the other strategies in establishing a niche in the introductions of research works. For instance, different studies indicate that postgraduate students rarely use this strategy in Spain (Salom et al., 2008), in Malaysia (Zainudden \& Shaari, 2017) and in the Iranian context (Farnia \& Barati, 2017; Mahzari \& Maftoon, 2007). The infrequent or non-usage of this strategy is not only found in the non-native context only, but also in native speakers of English context (e.g., Farnia \& Barati, 2017; Mahzari \& Maftoon, 2007; Wuttisrisiriporn, 2017). However, Ghanaian writers use this strategy as their second-best option (Adika, 2014; Davis, 2014).

Similar to 'Question raising', "Continuing tradition" is not one of the strategies writers prefer in establishing their niche. Spanish writers, for instance, tend to employ 'Continuing tradition' in establishing a niche almost the same as using question-raising strategy (e.g., Salom et al., 2008). In the context of Malaysia, graduate writers did not show much interest in using 'Continuing tradition' as a strategy in presenting their problem statement (Lim, 2012; Zainudden \& Shaari, 2017). In the context of Ghana and Iran, 'Continuing tradition' was considered a third best choice, although not all that significant (e.g., Adika, 2014; Farnia \& Barati, 2017; Mahzari \& Maftoon, 2007). Interestingly, Suryani, et al. (2018) provide a contrary report, suggesting that Malaysian writers' preference for 'Continuing tradition' strategy was very high.

The use of 'Counter claiming' by writers to establish the niche of introductions has produced varied results. While some studies report common usage of counter claiming, others report its rarity. Just like writers of Philippines (Porras \& Ingilan, 2017), Ghanaian writers rarely use this rhetorical strategy (Adika, 2014). However, Zainudden and Shaari (2017) show that Malaysian writers consider 'Counter claiming' as one of the key strategies (third choice) in establishing the niche of research introductions because it was found to be frequent in doctoral students' writings. Farnia and Barati (2017) found it to 
be the second-best choice of Iranian and native speakers of English writers; but in Spain and China, 'Counter-claiming' was not used (see Salom et al., 2008; Zhang \& Hu, 2010). In China, for instance, Zhang and $\mathrm{Hu}$ (2010) claim that writers try to avoid critical evaluation of previous research, but prefer positive review to reduce the effect of tone of evaluation.

So far, it can be established that several studies have been carried out in different parts of the world, specifically, focusing on how authors present 'establishing a niche' in the general introductions of academic research. It has also been established in the literature that studies in Ghana (e.g., Adika, 2014; Coker \& Coker, 2012, Davis, 2014) have not paid indepth attention to 'establishing a niche' of the introductions of undergraduate dissertations and postgraduate theses. This requires a detailed study of how Language students in the Department of English establish the niche of their introductions. The present study adopts the slightly modified CARS model to study the data.

\section{DATA AND METHODOLOGY}

This study employed the qualitative approach to investigate the rhetorical strategies used by undergraduate and postgraduate language students in the Department of English, University of Cape Coast (UCC), Ghana, in establishing their research niche. The content analysis approach was used to analyse the data. Some aspects of quantitative analysis, relying on frequencies and percentages, were employed to reveal the rhetorical patterns in the data.

Fifty-two (26 undergraduate and 26 postgraduate) language research works in the Department of English, University of Cape Coast, were collected (from 2009 to 2018) for the study. The theses were extracted from the database of the University of Cape Coast Thesis Repository, https://erl.ucc.edu.gh/jspui. Because the undergraduate student research works were not in electronic format, photocopies of the problem statement sections were made. The sample size was deemed suitable to enable us to identify the recurrent patterns because previous studies' data sizes on the same variable ranged from eight and about 100 (e.g., Zainudden \& Shaari, 2017; Soler-Monreal et al., 2011; Suryani et al., 2018; Salom et al., 2008; Lim, 2012; Parsa \& Tahririan, 2017).

\subsection{Method of Data Analysis}

The analysis started with coding the data, where two variables were considered: dissertation and thesis. The data for the undergraduates were assigned $D S 1, D S 2, \ldots$; and those for the postgraduates were assigned TS 1, TS 2, ... The content analysis approach was useful in identifying the rhetorical strategies used to establish the niche of the introductions in the data. The analysis was based on the CARS model proposed by Swales but only Move 2 (Establishing a niche) was of interest to this study. Just like Zainudden and Shaari (2017), the current study adopted the modified version of Swales' model, with the additional step of 'Establishing problem and need' which suited the strategies identified in the current study. The five steps in CARS M2 are described in a subsection below in order to facilitate the identification of the various steps in the data. 


\subsubsection{Identification of the Steps in Move 2 of CARS model}

In order to avoid redundancy, this section does not give detailed exemplifications of the Steps used but explanations that guided the identifications of the strategies employed by the language students in the Department of English in presenting the establishment of the research niche. It means that examples are used in the presentation and explanation of the results.

\section{Step 1A: Indicating a Gap}

According to Zainudden and Shaari (2017: 151), "a statement of gap indication suggests nonexistence, scarcity, or paucity of the research world". The writer gives the gap created by previous studies to establish the present study (Farnia \& Barati, 2017). Zainudden and Shaari claim that there are two main ways of expressing negative quantifiers and polarity in establishing a gap: explicit and implicit. The explicit means are carried through the negative quantifiers. Werle (2007) also indicates that different ways can be used to construct a sentence which signals nonexistence. It can be via negative quantifiers or polarity expressions. The negative quantifiers expressing nonexistence fall within the domain of no series, for instance, nothing, no one/nobody or never. For negative polarity, Cruse (2004) suggests expressions like anyone, anything, ever or any. However is often used. According to Zainudden and Shaari (2017), the writers implicitly express a gap without any specific indication of linguistic clues. Example can be seen in the expression like studies concentrated on.

\section{Step 1B: Establishing Need and Problem}

'The need and problem' expressions indicate claims which are related to theoretical issues or conceptual (Zainudden \& Shaari, 2017). These are more related to real-world problems. The problem, for instance, may revolve around a real-life observation and there is justification or the need to research into it. According to Samraj (2002), a problem statement is identified or recounted before justifying it with the need statement. Using the need strategy appears to project the problem of the study (Zainudden \& Shaari, 2017).

\section{Step 1C: Counter-Claiming}

According to Kwan (as cited in Zainudden \& Shaari, 2017), statements indicating counter-claims present some form of defects in a particular research practice. There is usually negative evaluation of the defects, pointing to shortcomings of a research design/theory Negative evaluation can also encompass the insufficiency of research outcomes. The writers' views oppose previous studies (Farnia \& Barati, 2017). It means that 'Counter claiming' usually relies on existing claims of similar previous studies (Zainudden \& Shaari, 2017). These ideas guided 'Counter claiming' identification in the present study.

\section{Step 1D: Continuing Tradition}

'Continuing tradition' denotes a continuation of previous study's practices. Zainudden and Shaari (2017), following Kwan, claim that the research theory, design, or instrument of a previous research might be replicated by a different study. The new study forms its principles on a similar previous study. This argument forms the basis for identifying this rhetorical strategy in the current data. 


\section{Step 1E: Question Raising}

In creating research space, questions are either directly or indirectly raised, according to Zainudden and Shaari (2017), to drive a study. The question the writer raises is usually based on issues related to a previous research (Farnia \& Barati, 2017; Wuttisrisiriporn, 2017). Cruse (2004) raises two elements of question raising: "asking feature" and "what is asked". The "answer-value" is seen at the results section of the study.

Based on these explanations and exemplifications of the Steps in establishing a niche of research introductions, the steps were identified in the data to organise into the various groupings in order to discuss the kind of strategies used by the undergraduate and postgraduate language students.

\section{RESULTS AND DiSCUSSION}

In this section we present the results and discussion of the analysis of the data. The section covers the rhetorical strategies used by the students.

\subsection{Rhetorical strategies of niche establishment (in the theses/dissertations)}

This subsection presents the results of the frequency distribution of the rhetorical strategies the students employed in persuading the readers on the need for their study. Table 1 displays the steps/strategies used, the frequency and percentages of distribution. The PG and UG represent postgraduates and undergraduates respectively.

Table 1 Frequency of strategies of introductions (M2) in the theses/dissertations

\begin{tabular}{|l|c|c|}
\hline Steps (1A-1E) & Frequency =36(PG) & Frequency =27 (UG) \\
\hline Indicating a Gap & $22(61.1 \%)$ & $14(51.9 \%)$ \\
Esta. Problem \& Need & $6(16.7 \%)$ & $12(44.4 \%)$ \\
Counter-Claiming & $5(13.9 \%)$ & - \\
Continuing Tradition & $3(8.3 \%)$ & $1(3.7 \%)$ \\
Question Raising & - & - \\
\hline Only 1 strategy & 21 & 25 \\
Multiple strategies & 5 & 1 \\
\hline
\end{tabular}

As can be seen from Table 1, there are variations of strategies used in the theses and dissertations to some extent. In general, we see that the postgraduate students employed four strategies (Indicating a gap, Counter-claiming, Establishing problem and need, and Continuing tradition) while the undergraduates relied on three (Indicating a gap, Establishing problem and need, and Continuing tradition). This means that the difference between the two variables (PG and UG) is Counter-claiming. Moreover, while 21 out of 26 theses used only a single strategy, the rest of the five theses used two or more strategies together in establishing the niche of the studies. The highest number of strategies combined in a thesis to establish a niche was three (Problem and need, Counter-claiming and Indicating a gap). The reliance on multiple strategies leads to variation and creativity. Only one undergraduate student out of the twelve relied on two strategies in constructing a niche in a dissertation (Indicating a gap and Establishing problem and need), suggesting that the rest utilised only one strategy. This observed difference between the two levels might be 
due to experience and level of education. It is also possible that the undergraduates do not read the problem statement sections of the theses in the Department to familiarise themselves with them because that might be beyond their level.

According to Table 1, no student employed Question raising strategy in establishing a niche, which contrasts what earlier scholars found because it was common in the writings of both students in the two Faculties studied and also RA writings (e.g., Adika, 2014; Davis, 2014). This might be due to the fact that Davis, for instance, studied the corpus from the Faculty level, and not specifically to the Department of English. The difference might be a departmentally based. However, the students in the Department of English relied on it to construct their niche. The finding of the present study on Question raising is not surprising as all the empirical reports from different parts of the world, such as Spain, Malaysia and Iran have indicated the rarity of this strategy (Salom et al., 2008; Zainudden \& Shaari, 2017; Farnia \& Barati, 2017). The next few paragraphs discuss the details of the specific strategies used with exemplifications from the corpus.

\subsubsection{Indicating a Gap}

The results from Table 1 demonstrate that both undergraduate and postgraduate students accept 'Indicating a Gap' as the most prevalent strategy to establish the niche in the introductions of their research in the Department of English. We can see that the PGs used this rhetorical strategy 22 times $(61.1 \%)$ whereas the UGs usage constituted $51.9 \%$ (14 times). Generally, this finding collaborates what earlier researchers in Ghana or, at least, Department of English, revealed; that is, the writers adopt 'Indicating a gap' as their first choice in establishing a niche (e.g., Adika, 2014; Coker \& Coker, 2012; Davis, 2014). This finding is not surprising as it is similar to some findings reported from both native and non-native speakers of English around the globe (e.g., Farnia \& Barati, 2017; Lim, 2012; Mahzari \& Maftoon, 2007; Nimehchisalem et al., 2016; Samad et al., 2017;). However, this finding contrasts several studies which found 'Establishing problem and need' as the first choice (e.g., Zainudden \& Shaari, 2017; Jalilifar et al., 2011; Parsa \& Tahririan, 2017; Salom et al., 2008). The inconsistency in different geographical settings suggests that opting for either 'Indicating a gap' or 'Establishing problem and need' may be attributed to style and common practices. Moreover, the difference in percentage recorded between the two groups of students in this study shows that the PGs used the strategy more than the UGs. This might be due to how UGs greatly relied on their own observations to establish their niche. Examples (1) to (4) demonstrate this strategy.

Example 1:

Supra segmental phonology including pitch, intonation contours and rhythm was thus neglected. Rhythm, which is a fundamental element to the study and acquisition of language, is very often ignored in the study of English in Ghana. (TS 2)

Example 2:

... there seems to be few studies conducted on news bulletins in radio from a genre analysis perspective (Sarfo, 2011; Amoakohene, 2015). (TS 4)

Example 3:

While much research has been conducted on the language and style of Diaz's work, not much has been done particularly pertaining to the interaction between the language and cultural hybridity of the text.... (DS 3 ) 
Example 4:

Some other studies have also explored the tense system of English language. Writers such as Chodurova (2010) and Hamee (2008) have analysed the tenses of the newspaper in general and on headlines in newspapers. It appears that studies on editorials and tense have been neglected_...There this present study aims to show the English tense system ... (DS 17)

In Examples (1) to (4), we see that the boldened expressions mark the transition from the assessment of previous studies to the identification of what was not captured or areas of limitations. This means that, in order to proffer comments that are critical to address a specific gap in a research, students tend to stress the areas of previous studies that they deem problematic or unresolved (Farnia \& Barati, 2017; Samad et al., 2017). In simple terms, establishing a gap requires two steps: relying on previous studies and identifying the gap (Areas of previous studies + Gap). Writers employ this strategy to legitimately persuade their readers to accept their new entry into the discourse of a field.

\subsubsection{Establishing Problem and Need}

Although not highly significant as compared to Indicating a Gap, Establishing Problem and Need were used by both the undergraduates and postgraduates as the second preferred rhetorical strategy for establishing their research niche (see Table 1). The results show that this strategy was not evenly distributed in both UG and PG writings. In the case of the PGs, the frequency difference between this strategy and Counter-claiming indicates that they were used almost the same. To the PGs, this strategy was not regarded highly significant in establishing a niche because it recorded frequency of only $16.1 \%$, as compared to the first choice. A possible reason is the fact that reading the literature to find a gap can be a challenging task for students (Wuttisrisiriporn, 2017). However, the occurrence of this strategy in the case of the UGs was different. The frequency of usage by the undergraduates suggests that it was employed almost the same as the first choice (Indicating a gap). It is possible that establishing a niche from observed life situations was easier to some of the undergraduates than making time to read extensively to in search of a gap. The use of this rhetorical strategy was not specifically reported by the studies that examined Ghanaians writing of their research niche (see Adika, 2014; Davis; 2014; Coker \& Coker, 2012). The findings about this rhetorical strategy contrast what was found elsewhere in Spain, Malaysia, and Iran because writers adopted it as their first choice to establish a niche of their research problem statements (Jalilifar et al., 2011; Salom et al., 2008; Zainudden \& Shaari, 2017). Possibly, the difference depends on research focus as the first-choice usage contexts deal mostly with language teaching and learning research, unlike the Department of English being studied. Extracts (5) to (8) exemplify this strategy.

Example 5:

The spread of English has ushered in a fascinating area of research of the English language in the last two decades. This is so because the spread has led to the emergence of several varieties of the language all over the world, including the Ghanaian variety [Problem] and, therefore, requires attention [Need]. (TS 2) 
Example 6:

Good writing needs to be clear as possible so that reader can easily follow sentences, ideas and details. Thus, when students present their ideas in writing tasks, they are expected to ensure text flow. ... Olga et al. (2009) believe that "since English has become the 'lingua franca' of the modern world, research into cohesion strategies in English discourse is considered relevant to all spheres of human communication" [Problem]. This study, therefore aims at investigating how the senior high school students handle grammatical cohesive devices to achieve cohesion in their narrative and argumentative essays [Need]. (TS 19)

Example 7:

It is noteworthy that ambiguity creates misleading impressions in the minds of readers of the popular press [Problem]. This essay aims to highlight the problem of ambiguity in the print media. ...The researcher will offer some suggestions on how to avoid ambiguity in language use [Need]. (DS 10)

Example 8:

This current situation makes it difficult for people to tolerate, recognise and accept certain variants that serve to distinguish Ghanaian English and NEs, notably British English, as innovative and legitimate differences rather than as deficit characteristics. ...[Problem]. There should be adequate studies that reveal the characteristic uses of Ghanaian English in all aspects of language study. This way, there can eventually be the codification of Ghanaian English usage for a proper recognition of divergent forms. It is in this regard that this study is timely [Need]. (TS 7)

In Examples (5) to (8), the need for conducting a new research is preceded by the observed problem. It must be noted that the need for doing the study is boldened in each example but the stated problem is not. Mostly, the problems were general observation or life practical challenges the researchers identified which were mostly introspectively based phenomena. For instance, Example 5 proffers some general observation (the Problem) preceding the need to do further investigation. The Need is marked by the expression "therefore, requires attention". In Examples 7 and 8, real problems are identified: the problem of ambiguity, and the problem of tolerability and acceptance of Ghanaian English respectively. The boldened expressions in each case highlight the necessity to do a study to resolve the identified problems. We can see that the three instances did not have to necessarily rely on previous studies. It means that, after indicating the existing observed problems, the second segment required the need to investigate the problem. This rhetorical strategy quite differs from 'Establishing a gap' because the researchers looked for a gap in the previous studies in order to create a research space in the latter, while the former relied on a practical observed phenomenon.

\subsubsection{Counter-Claiming}

Besides the two highly frequent strategies, Counter-claiming became the third preferred choice in the theses although its frequency is marginal to Establishing problem and need (see Table 1). It is important to note that it occurred in the thesis only, suggesting that the UGs did not use it to justify the necessity of their studies. The presence of the use of 
Counter-claiming in the data occurred similarly like what was found in Malaysia (Zainudden \& Shaari (2017). However, this finding contrasts what Coker and Coker (2012) and Davis (2014) found. This might be due to the focus of the previous studies and the present one, as the current study appeared more detailed and concentrated on only M2. In fact, it is important to discuss the level of occurrence of this strategy in the data due to the fact that its rare use has been reported by Adika (2014). Although Counter-claiming appears not to be highly preferred choice (only 5 times), it seems to be the highest critical evaluative act the students engaged in. For one to critically and legitimately criticise the weakness of theories, concepts or a study's results/findings requires higher order thinking skills, in our ratings. Most students probably avoided this strategy in order to avoid showing commitment to people's finding. However, its application in an evaluative act shows the hallmark and beauty of academic excellence. Examples 9 and 10 show how the students constructed the Counter-claiming strategy:

Example 9:

However, the popular view in contact linguistics is that only first languages have the capacity to interfere with second languages of the bilingual (Akande and Akinwale 2006, Cook 1993, Crystal 1997 etc.). This study seeks to contest this popular view by ascertaining whether the otherwise is also possible. (TS 4)

\section{Example 10: \\ Moreover, Seward (2012) tried to enumerate some ideal ways of writing a good company profile. However, his work was not an empirical study and therefore, the elements he mentioned cannot be relied upon as the schematic structure of company profile._Against this background, I seek to explore this emerging field of internet genres in order to produce an empirical study which to a large extent can make insightful contribution to the literature on company profile. (TS 18)}

We note from Examples 9 and 10 that the authors make certain claims, the boldened expressions, which contest certain earlier claims in the literature (those that precede the boldened expression). This is an indication that the authors do two basic things: rely on previous studies' claims and provide the counter-claim. What the counter claim seeks to do is to indicate that the new study has the potential to challenge a previous claim or finding. This observation confirms what is already espoused in the literature (e.g., Swales, 1990; Farnia \& Barati, 2017; Zainudden \& Shaari, 2017). This means that the researcher holds some hunches or a priori ideas which are considered to be far better to override the already existing knowledge in the previous studies. When a researcher reads the results of a study or concept brought forward by either empirical evidence or introspective means, this may lead him/her to embark on another study to prove the opposite of it. In such instance, the new study creates a research space by counter-claiming what is already there.

\subsubsection{Continuing Tradition}

The results show that Continuing tradition was used by both undergraduates and postgraduates in establishing a niche, although not all that significant in terms of frequency. The study recorded rare use of it, as it occurred once in the UG writings but thrice in the PG writings. The occurrence of this strategy in the study is close to what Adika (2014) found in Legon Journal of the Humanities, as being five in the RAs. This means that it was not one 
of the main strategies the students or writers prefer in constructing their problem statement sections. Surprisingly, this finding is at variance with Coker and Coker's (2012) finding in the same Department of study because it was not discovered in the data used. Nevertheless, it confirmed what was found in the Faculty of Arts by Davis (2014), probably because other members or departments of the Faculty of Arts found its usage useful to create a research space to enter into the research discourse. Reports from Iran (Farnia \& Barati, 2017), and Spain (Salom, et al., 2008) suggest similar usage of Continuing tradition as found in this study. However, in Malaysia, two contrasting reports are given: one reveals its usage as the best choice by Malaysian writers (e.g., Suryani et al., 2018), but the other point to very infrequent usage (Zainudden \& Shaari, 2017). Two examples are provided in (11) and (12). The boldened expressions mark the rhetorical strategy.

Example 11:

Bhatia indirectly points at the promotional nature of blurbs although his analysis focuses on the mixing of private intentions with conversational communication purposes in academic introductions. In contrast, this present study departs from existing research, in that it rather solely attempts to explore the persuasive language techniques in the blurbs of language. [D 9]

Example 12:

Her discourse analysis of four public universities revealed that there is a gradual shift from academic discourse to marketization discourse in the running of these institutions. Therefore, there is the need for further empirical evidence either to augment the claims. [TS 11]

We can see from the two examples $(11 \& 12)$ that the boldened expressions are used to acknowledge the contributions of the previous studies, and at the same time announce the studies' intentions to add more evidence to support the existing knowledge. In example (11), the author demonstrates that the current study differs from the previous one by utilising the expression "this present study departs from existing research", but the second one declares the intention to augment earlier claims. All these are indicators of supporting or adding to what is already known - they do not explicitly look for any gap in the previous studies. This rhetorical strategy appears to be the weakest evaluative exercise if the study is not able to vehemently justify the need to add to what is already known, if not for verifying claims or theories. It could be more useful to also combine this rhetorical strategy with other ones to achieve a better persuasive effect of negotiating one's entry into a research dialogue.

\subsubsection{Multiple strategies}

There were few instances where some students used a combination of strategies and these were regarded as multiple strategies (see Table 1). This style of combination seems not to be explicitly discussed in many studies. Example 13 demonstrates a clear case of multiple strategies in the data.

Example 13:

The spread of English has ushered in a fascinating area of research of the English language in the last two decades. This is so because the spread has led 
to the emergence of several varieties of the language all over the world, including the Ghanaian variety [Problem] and, therefore, requires attention $[$ Need $] ..$.

The descriptions on rhythm and prominence of Ghanaian English tended to focus on auditory perceptions. As a result, to date there is a dearth of research based on features of prominence and rhythm in Ghanaian English [GAP] ... This research, therefore, embarked on an investigation into the nature of features of ... [TS 3]

Example 13 demonstrates two rhetorical strategies: Problem and need, and Indicating a gap. The writer tries to negotiate her entry into the research space by, first of all, counting on observed phenomenon (emergence of varieties of English) with some backing explanations. Because there is a new variety of English (Ghanaian English), it provides enough space for it to be investigated adequately. Additionally, the writer reinforced the problem statement by introducing another strategy (Indicating a gap) in trying to establish a specific gap which has not been covered by the previous research. This act marks a combinatorial strategy and not a way of necessarily extending the first one.

\section{CONCLUSION}

This study aimed to explore the rhetorical strategies of establishing a niche in the introductions of language students in the Department of English of a Ghanaian university, UCC. A modified Swales' CARS model was used to identify the rhetorical strategies in establishing a niche in the data. The study identified four strategies in all: Indicating a gap, Establishing problem and need, Counter-claiming, and Continuing tradition. These strategies were used to negotiate entry into the new study. Apart from 'Counterclaiming', the UG students used the rest. The most frequently used rhetorical strategy for both PG and UG writers was 'Indicating a gap', but the least was 'Continuing tradition'. 'Question raising' was not identified in the data studied. 'Indicating a gap' required more engagement with the literature than employing 'Establishing problem and need' strategy.

It is important to enlighten students on the varied means of presenting problem statement of research works in order to encourage creativity and variation in presenting the section. This is because studies that closely follow the strategies in CARS model are cited highly (Suryani et al., 2015). In the face of available options for common practices, the students keep to three main strategies in establishing a niche in introductions of research in the Department of English, UCC. These novice writers are being oriented in the academic discourse community to learn the common and best practices. Ahlstrom (2017) claims that writers who fail to present interesting and specific focus of research introductions do not meet the demands of editors and reviewers. Therefore, exposing students to various strategies is useful.

This study's findings are crucial in contributing to pedagogy and academic writing, especially in the Departments of English. This is due to the fact that introduction section of research works is regarded very complicated (Samad et al., 2017; Swales, 1990). Abdullah (2016) claims that the introduction section provides the synopsis of a research to readers and therefore its organisation should be in a position to clarify its focus and make the problem significant. Besides, proposal and thesis' introduction writing has been 
found to be very challenging to postgraduate students (Jalilifar et al., 2011), let alone undergraduates. The findings of this study offer a reflection of some common practices in the Department of English, UCC, which throws a challenge to the students to improve their academic writing skills in research. Apart from the content of a research paper, it is the application of appropriate academic writing skills in the different sections of the RP that makes it achieve its clarity and definable purpose.

\section{REFERENCES}

Abdullah, S. (2016). An analysis of cross-discipline research article introduction structures through a modified create-a-research-space (CARS) model. EFL Journal, 1(1), 1-16.

Adika, G. S. K. (2014). Swales' CARS model and the metaphor of research space: An illustration with an African Journal. Legon Journal of the Humanities, 25, 58-75. DOI: http://dx.doi.org/10.4314/ljh.v25il.4

Afful, J. B. A. (2008). Research proposal and thesis writing: Narrative of a recently graduated researcher in applied linguistics. Nebula, 5(4), 193-211.

Ahlstrom, D. (2017). How to publish in academic journals: Writing a strong and organised introduction section. Journal of Eastern European and Central Asian Research, 4(2), 19. DOI: http://dx.doi.org/10.15549/jeeca.v4i2.180

Bhatia, V. K. (1993). Analysing genre: Language use in professional settings. London and New York: Longman.

Coker, W. \& Coker, W. (2012). Stating the research problem: A genre-based study of English language MPhil theses in a Ghanaian university. Language in India, 12, 509-518.

Cruse, D. A. (2004). Lexical facets and metonymy. Ilha Do Desterro a Journal of English Language, Literatures in English and Cultural Studies. 47, 73-96.

Davis, W. C. (2014). A genre analysis of the statement of the problem section of masters' theses in two faculties in the University of Cape Coast. Unpublished Thesis in the Department of English, UCC.

Farnia, M. \& Barati, S. (2017). Writing introduction sections of research articles in applied linguistics: Cross-linguistic study of native and non-native writers. Indonesian Journal of Applied Linguistics, 7(2), 248-256. doi: dx.doi.org/10.17509/ijal.v7i2.8357

Jalilifar, A. R., Firuzmand, S. \& Roshani, S. (2011). Genre analysis of problem statement sections of MA proposals and theses in applied linguistics. The International JournalLanguage Society and Culture, 33, 85-93.

Lim, M. (2012). How do writers establish research niches? A genre-based investigation into management researchers' rhetorical steps and linguistic mechanisms. Journal of English for academic purposes, 11, 229-245.

Mahzari, A. \& Maftoon, P. (2007). A genre analysis study of Iranian EFL learners' master theses with a focus on the introduction. Theory and Practice in Language Studies, 1(3), 201-214.

Neuman, W. L. (2007). Social research: Qualitative and quantitative approaches. Boston: Pearson Education Inc.

Nimechisalem, V. Tarvirdizadeh, Z. Paidary, S. S. \& Hussin, N. I. B. (2016). Rhetorical moves in problem statement section of Iranian EFL postgraduate students' theses. Advances in Language and Literary Studies, 7(4), 173-180. Doi:10.7575/aiac.alls. v.7n.4p.173 
Parsa, S. \& Tahririan, M. H. (2017). Move structure in "statement-of-problem" sections of MA theses: The case of native and non-native speakers of English. Iranian Journal of Applied Linguistics, 20(2), 195-228.

Porras, A. \& Ingilan, S. S. (2017). Genre analysis of linguistic research introductions. Multidisciplinary Research Journal, 2(1). Accessed from https://www.academia.edu.

Salom, L. G., Monreal, C. S., \& Olivares, M. C. (2008). The move-step structure of the introductory sections of Spanish PhD theses. RESLA, 21, 85-106.

Samad, I. A., Usman, B., Rizkanisa, N. \& Fitriani, S. S. (2017). Non-native speakers' rhetorical commonalities in writing script introduction section. Lingua Cultura, 12(2), 141-147. https://doi.org/10.21512/1c.v12i2.2475

Samraj, B. (2002). Texts and contextual layers: Academic writing in content courses. In A. M. Johns (Ed.). Genre in the classroom (pp. 163-177). Mahwah, NJ: Lawrence Erlbaum Associates, Inc.

Shirani, S. \& Chalak, A. (2016). A genre analysis study of Iranian EFL learners' master theses with a focus on the introduction. Theory and Practice in Language Studies, 6(10), 1982-1987. DOI: http://dx.doi.org/10.17507/tpls.0610.13

Soler-Monreal, C., Carbonell-Olivares, M., \& Gil-Salom, L. (2011). A Contrastive study of the rhetorical organisation of English and Spanish PhD thesis introductions. English for Specific Purposes, 30(1), 4-17.

Suryani I, Aizan, Y. \& Aziz, N. H. A. (2015). Introduction sections of research articles with high and low citation indices. Pertanika Journal of Social Science and Humanities, 23(4), 1139-1152.

Suryani, I., Ahmad, N., Zubir, F., Ghazali, N. \& Aclan, E. M. (2018). Description on research article introduction section by computer science researchers in Malaysian private universities. Journal of Human Development and Communication, 7, 1-8.

Swales, J. M. (1990). Genre analysis: English in academic and research settings. Cambridge: Cambridge University Press.

Swales, J. M. \& Feak, C. B. (2012). Academic writing for graduate students: Essential tasks and skills ( $3^{\text {rd }}$ ed.). Michigan: Michigan ELT.

Werle, A. (2007). A typology of negative indefinites. University of Massachusetts, Amherst. Retrieved from https://web.uvic.ca

Wuttisrisiriporn, N. (2017). Comparative rhetorical organisation of EFT thesis introductions composed by Thai and American students. English Language Teaching, 10(12), 1-14. http://doi.org/10.5539/elt.v10p1

Zainudden, S. Z. \& Shaari, A. H. (2017). Contextual layers in the establishment of research niche in doctoral thesis introductions in Malaysian writers. GEMA Online Journal of Language Studies, 17(2), 146-162. http://doi.org/10.17576/gema-2017-1702-09

Zhang, Y. \& Hu, J. (2010). A genre-based study of medical research article introductions: A contrastive analysis between Chinese and English. The Asian ESP Journal, 6(1), 72-96. 